\title{
Effect of irrigation amount and frequency on phenology, vine length and biomass partitioning of wild cucumber (Cucumis myriocarpus) and wild watermelon (Cucumis africanus)
}

\author{
R. J. Nkgapele, M. S. Mphosi \& P. W. Mashela \\ Department of Soil Science, Plant Production and Remote Senses, \\ School of Agricultural and Environmental Sciences, \\ University of Limpopo, South Africa
}

\begin{abstract}
This study was conducted to determine the most suitable irrigation frequency and quantity for the greenhouse-grown indigenous leafy vegetable, Cucumis myriocarpus, and herbage crop, Cucumis africanus. Four irrigation intervals were tested, 2, 3, 4 and 5 days, arranged in a randomised complete block design. Total irrigation quantities, plant water consumption, rate of progress towards flowering and vine length varied amongst the irrigation frequency treatments, whereas biomass partitioning to botanical fractions differed only in the roots of C. myriocarpus. The highest yields were obtained from treatments employing the middle ( 3 and 4 days intervals) frequencies and quantities of irrigation. Results of the study suggest that proper management strategies of irrigation amount and frequency can improve the quality and quantity of $C$. myriocarpus and C. africanus for sustainable rural smallholder crop production system augmentation in the Limpopo Province of South Africa.

Keywords: classical growth, biomass yield, root/shoot ratio, water use efficiency, vine length, leaf parameters.
\end{abstract}

\section{Introduction}

Wild cucumber (Cucumis myriocarpus) and wild watermelon (C. africanus) are important indigenous food and medicinal plants in semi-arid areas of Southern 
Africa, where they mainly grow naturally. Fruits are highly toxic and not edible by both humans and livestock [1], but they are widely used for ethnomedicine and ritual purposes. The toxic principles are the triterpenoids known as cucurbitacins $[2,3]$. Leaves of $C$. myriocarpus are collected in the wild for use as a cooked vegetable, whereas those of C. africanus are not edible [4].

Water requirements for the production of $C$. myriocarpus and $C$. africanus are currently not documented. The objective of the study was to determine the effects of water applications on agronomic performance in relation to crop phenology, growth and plant fraction biomass accumulation and partitioning.

\section{Materials and methods}

\subsection{Study location/area}

Separate experiments for C. africanus and C. myriocarpus were conducted at the Horticultural Unit of the University of Limpopo, South Africa (2353'10" S; $29^{\circ} 44^{\prime} 15^{\prime \prime}$ E) under greenhouse conditions during the 2009/2010 growing season. Ambient day/night temperatures averaged $28 / 21^{\circ} \mathrm{C}$, with maximum temperatures controlled using thermostatically-activated fans.

\subsection{Procedures}

Fruits of $C$. africanus and $C$. myriocarpus were collected from the local field, cut into pieces, seeds removed and shade-dried for 14 days. Seeds were separately wrapped in hand-sewn cotton handkerchief bags and submerged in running tapwater for 8 hours to leach out the germination-inhibiting chemicals prior to planting in seedling trays containing Hygromix growing medium [5]. Thirty-cmdiameter plastic pots, filled with $10 \mathrm{~L}$ steam-pasteurised sand and Hygromix (3:1 $\mathrm{v} / \mathrm{v}$ ), were placed on greenhouse benches at $0.5 \mathrm{~m}$ inter-row and $0.6 \mathrm{~m}$ intra-row spacing. Uniform three-week-old, Cucumis seedlings were transplanted to the pots for separate studies one day after irrigating the growing medium to field capacity.

The five treatments for evaluating crop phenology, growth rate and plant fraction biomass accumulation and partitioning, namely $0,2,3,4$ and 5 irrigation intervals (days), were arranged in a randomised complete block design, with five replicates. During each irrigation interval, $1000 \mathrm{ml}$ tap-water was applied per pot.

\subsection{Data collection}

Flowering was scored when the 50\% flowers appeared. At harvest, 84 days after initiating the experiments, vine length was measured, shoots were cut at the soil level and root systems were removed from pots, immersed in water to remove soil particles and blotted dry. Plants were separated into roots, stem and leaves. Leave were passed through leaf area meter (LI-3300C) to determine leaf area, width and length. Shoots and their respective roots were oven-dried for 72 hours at $60^{\circ} \mathrm{C}$ and weighed for the determination of dry biomass. 


\subsection{Data analysis}

Data were subjected to analysis of variance using STATISTIX 8 software to determine treatment effects. Mean comparison among treatments were performed using LSD test at 5\% level of probability.

\section{Results and discussion}

Rate of progress towards flowering phenological stages, crop growth rate and biomass yield varied and similar patterns amongst the irrigation frequency treatments. The highest biomass partitioning to plant fractions were obtained from treatments employing the intermediate and frequent water application intervals.

\subsection{Flowering and rate of progress to flowering}

The most critical of phenological stages in most herbage is flowering because after the onset of flowering most herbage plants become undesirable. Differences on the rate of progress to flowering were observed in $C$. africanus, and not in C. myriocarpus. This suggested that $C$. myriocarpus could thrive well when water availability is not a growth limiting factor. The research on agronomic crops has focused on a methodology to predict the time taken to flower. Analyses of experimental observations have shown the advantages of using the developmental rate for flowering $(1 / f$, defined as the reciprocal of the number of days from sowing to $50 \%$ flowering), instead of the actual number of days to flowering [6-8].

Irrigation frequency effects on C. africanus exhibited significant $(\mathrm{P} \leq 0.05)$ differences with regards to the number of days taken to flower and rate of progress to flowering stage with 4 and 5 days irrigation intervals showing the shortest and longest periods, respectively (Table 1).

Table 1: Flowering and rate to flowering in Cucumis africanus under 5 irrigation intervals.

\begin{tabular}{|c|c|c|}
\hline $\begin{array}{c}\text { Irrigation } \\
\text { interval } \\
\text { (days) }\end{array}$ & $\begin{array}{c}\text { Days to } \\
\text { Flowering }(f)\end{array}$ & $\begin{array}{c}\text { Rate of } \\
\text { progress }(1 / f)\end{array}$ \\
\hline 0 & $38 \mathrm{ab}$ & $0.0260 \mathrm{ab}$ \\
\hline 2 & $38 \mathrm{ab}$ & $0.0260 \mathrm{ab}$ \\
\hline 3 & $38 \mathrm{ab}$ & $0.0260 \mathrm{ab}$ \\
\hline 4 & $37 \mathrm{~b}$ & $0.0270 \mathrm{a}$ \\
\hline 5 & $39 \mathrm{a}$ & $0.0256 \mathrm{~b}$ \\
\hline
\end{tabular}

Column means with the same letter were not different at 5\% LSD test. 
In C. myriocarpus, average days to flowering were 38.8 days across the irrigation frequency treatments. The highest days to flowering (40 DAT) were exhibited by the 3-day irrigation frequency which was $5.3 \%$ higher than the least to flowering (38 DAT). The rate of progress towards flowering $(1 / f)$ was similar across the treatments and had an average rate of 0.026 .

\subsection{Vine length}

Vine length measurement is one of the simple tools that can be employed to measure crop growth in resource poor smallholder farming systems since it requires little instrumentation. During the initial stages (7 DAT) significant differences in plant height $(\mathrm{P} \leq 0.009)$ were only observed in $C$. africanus. Plant height varied throughout the vegetative growth stage among the irrigation frequency treatments and between the two species (figure 1). This shows that

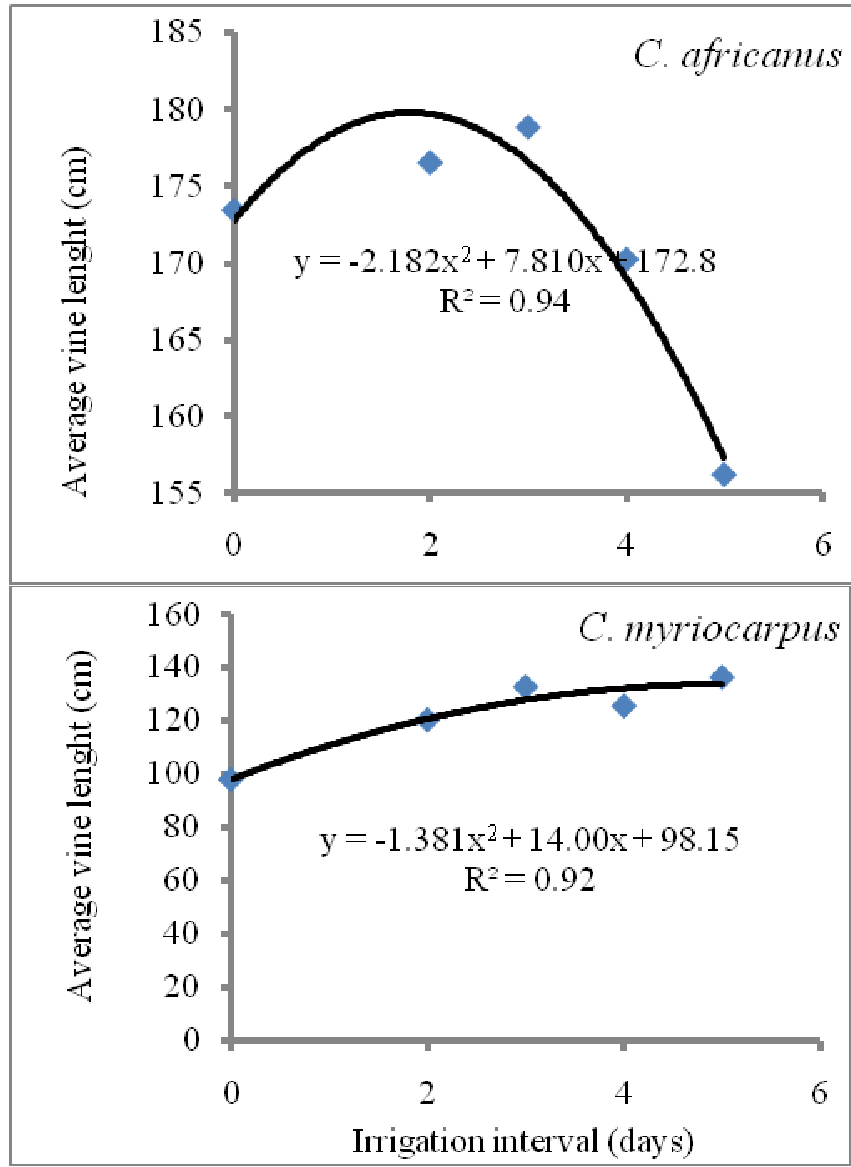

Figure 1: Average vine length during the vegetative growth stages at 5 irrigation intervals. 
water application has a bearing on plant growth especially during the early vegetative growth stages.

\subsection{Biomass partitioning}

Plant growth performance is determined by the plant's ability to accumulate dry matter. Plant biomass, computed in this case as dry weight of the individual botanical fractions, is regarded in crop physiology as plant's accumulation of photosynthetic products [9]. Root biomass differed across the irrigation frequency in $C$. myriocarpus (figure 2) with more frequent intervals showing higher biomass and less frequent intervals lower biomass. This result indicate that water has effects on assimilate distribution to the root of the crop as opposed to the other plant fractions which showed no effects. Watering frequency had no effect on botanical fractions of $C$. africanus. It is important to understand the effects water on botanical fractions if these indigenous crops are to be grown successfully using conventional ways of production.

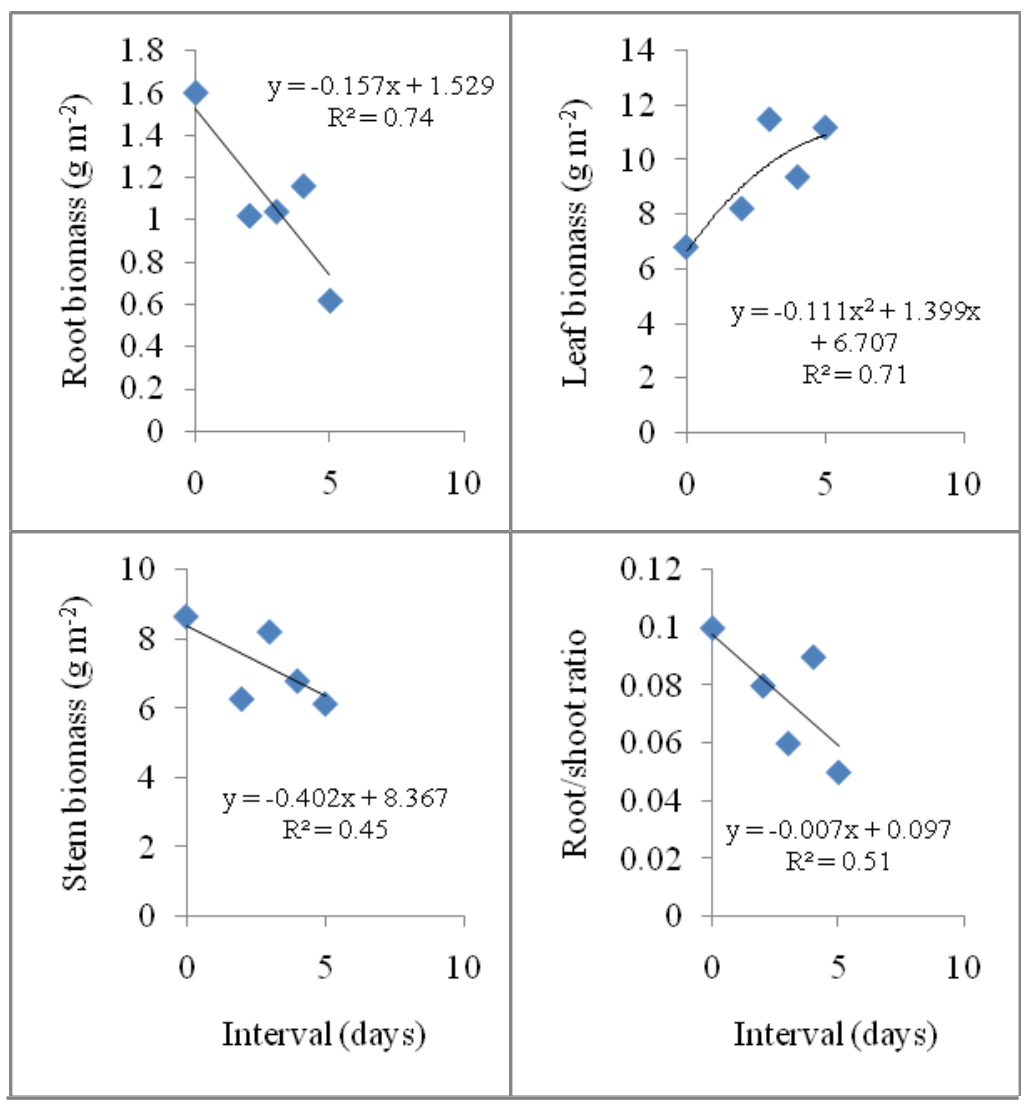

Figure 2: Plant fraction biomass and root/shoot ratios in C. myriocarpus under 5 irrigation intervals. 

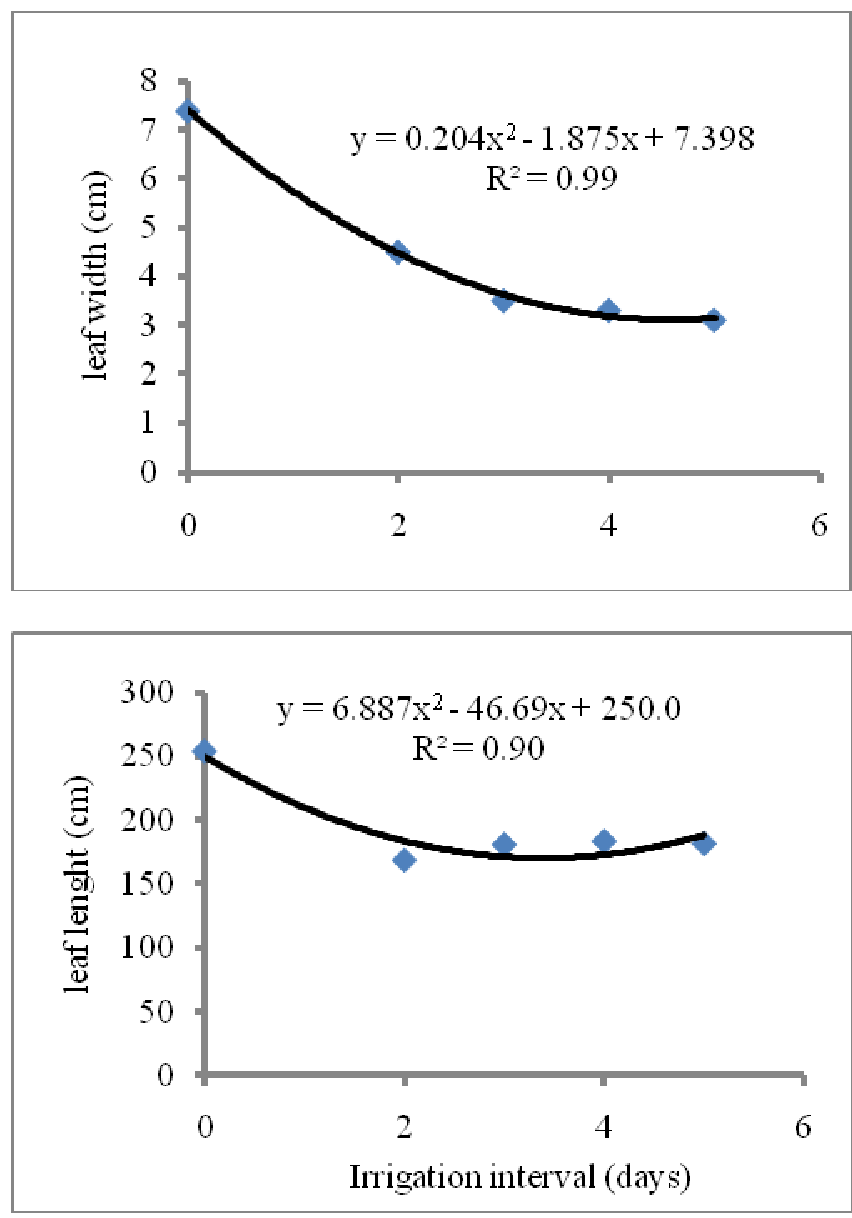

Figure 3: Leaf fraction analysis in C. africanus under five irrigation intervals.

The non-significant $(\mathrm{P} \leq 0.05)$ yield trend depicted in $C$. africanus the of favour the sustainability goals of applying deficit irrigation and supplemental irrigation water saving management strategies, since the crop can endure long periods of no water supply without affecting biomass partitioning and consequently yield.

\subsection{Analysis of leaf fractions}

In $C$. myriocarpus, leaf area was highest in the intermediate (3 days) irrigation water application frequencies at $37.7 \%$ higher than the lowest area exhibited in 2 day irrigation interval. The average leaf area across the irrigation frequencies was $202.9 \mathrm{~g} \mathrm{~mm}^{-2}$, which was $13 \%$ lower than the highest area and $19.7 \%$ higher than smallest leaf area. Leaf width and length where similar and averaged at 3.1 and $90.7 \mathrm{~cm}$, respectively. 
In contrast, $C$. africanus exhibited differences $(\mathrm{P} \leq 0.05)$ in response to irrigation frequency on the leaf structural properties measured. Leaf area was highest in 2 day interval irrigation frequency, while leaf width and length where more pronounced in the no interval regime (figure 3 ).

\section{Conclusions}

Cucumis myriocarpus and $C$. africanus can be successfully produced using conventional water application methods. The potential to add value to the resource-poor smallholder farming systems in the Limpopo Province of South Africa is immense. The potential the two species possess, to produce high quantity biomass under less frequent irrigation can assist in water saving strategies that are so eminently required for sustainability promotion in smallholder irrigation systems.

\section{References}

[1] Botha, C.J., \& Perinth, M.L., Poisonous plants of veterinary and human importance in southern Africa. Journal of Ethnopharmacology, 119, pp. 549-558, 2008.

[2] Chen, J.C, Chiu, M.H, Nie, R.L., Cordell, G.A., \& QIU, S.X., Cucurbitacins and Cucurbitane Glycosides: Structure and Biological Activities. National Production Report, 22, pp. 386-399, 2005.

[3] Halaweish, F.T., \& Tallamy, D.W., A new cucurbitacin profile for cucurbita andreana: a candidate for cucurbitacin tissue culture. Journal of Chemical Ecology, 19, pp. 1135-1142, 1993.

[4] Kirkbride, J.H., Biosystematic Monograph of the Genus Cucumis (Cucurbitaceae): Botanical Identification of Cucumbers and Melons. Parkway Publishers: North Carolina, pp. 92-104, 1993.

[5] Mafeo, T.P. \& Mashela P.W., Responses of germination in tomato, watermelon and butternut squash to Cucumis bionematicide. Journal of Agriculture and Environment Science 6, pp. 215-219, 2009.

[6] Brink, M. Rates of progress towards flowering and podding in bambara groundnut (Vigna subterranea) as a function of temperature and photoperiod. Annals of Botany, 80, pp. 505-513, 1997.

[7] Brink, M. Development, growth and dry matter partitioning in bambara groundnut (Vigna subterranea) as influenced by photoperiod and shading. Journal of Agricultural science, 133, pp. 159-166, 1999.

[8] Linnemann, A.R., \& P.Q. Craufurd. 1994. Effects of temperature and photoperiod on phenological development in three genotypes of bambara groundnut (Vigna subterranean). Annals of Botany, 74, pp. 675-681, 1994.

[9] Tesar, M.B. Physiological basis of crop growth and development, American Society of Agronomy, Inc., \& Crop Science Society of America, Inc.: Madison, Wisconsin, USA, pp. 240-264,1984. 